\title{
3D Modeling of the Milreu Roman Heritage with UAVs
}

\author{
José Rodrigues $^{1(\bowtie)}$, Mauro Figueiredo ${ }^{1}$, João Bernardes ${ }^{2}$, \\ and César Gonçalves ${ }^{1}$ \\ 1 University of Algarve - ISE, PT, Faro, Portugal \\ \{jirodrig, mfiguei, cgoncal\}@ualg.pt \\ 2 University of Algarve - CEAACP, PT, Faro, Portugal \\ jbernar@ualg.pt
}

\begin{abstract}
In this paper we present a methodology to build a 3D model of a roman heritage site in the South of Portugal, known as Milreu, covering a region of about one hectare. Today's Milreu ruins, a national heritage site, were once part of a 4rd century, luxurious villa-style manor house, which was subsequently converted into a thriving farm. Due to its relevance, it is important to make the 3D model of the Milreu ruins, to be available for the exploration in the Web and for virtual and augmented reality applications for mobile devices. This paper demonstrates the use of UAVs for the reconstruction of the 3D models of the ruins from vertical and oblique aerial photographs. To enhance the model quality and precision, terrestrial photographs were also incorporated in the workflow. This model is georeferenced, which give us the possibility to automatically determine accurate measurements of the Roman structures.
\end{abstract}

Keywords: 3D models - web3D - UAV · Digital photogrammetry · Cultural heritage

\section{Introduction}

Milreu ruins, located in Estoi, $7 \mathrm{Km}$ from Faro (Fig. 1), were part of a larger complex that consisted of a villa, farm buildings, a Roman-style bath, a wine press, and a temple devoted to the aquatic deities. There are also signs that the Romans had a fairly evolved water supply-and-drainage system. One of the unique features of the manor house is the use of stones like marble and striking, patterned mosaics depicting marine life.

The creation of an archaeological virtual model is useful for different purposes such as preservation, reconstruction, as-built documentation and museum exhibitions [13] in which visitors can explore a 3D interactive and immersive environment, enhancing the exploration of the hidden history of Milreu. The three-dimensional virtual reconstruction of Milreu roman ruins, shows to the general public, in a more obvious way, the importance and the true scale that this archaeological site was for 1700 years ago. 
The 3D model in this work is the support to build a virtual model of the Roman villa to show the original buildings of this Roman site. The user can visualize the $3 \mathrm{D}$ virtual models in a Web browser or visit the Milreu site and explore, with a mobile device that shows the 3D models superimposed with the real word, using augmented reality.

The surveying of archaeological sites using drones has now become common due to its importance for preservation, reconstruction, as-built documentation and even museum exhibitions. The quality of processed measurements has reached a level of accuracy [10] sufficient to convince the cultural heritage community. Some applications has been made and are known in the bibliography such as presented by Rinaudo et al. [10] where the authors describe the process to generate the digital surface model (DSM) and orthophoto of a Roman villa archaeological site located in Aquileia (Italy), a well-known UNESCO WHL site. Identical approach was adopted by Seitz and Altenbach [16] but moreover than image mosaics, they also delivered a 3D model of in Germany and Cambodia. Fiorillo et al. [5] integrated photogrammetry and terrestrial laser scanning (TLS) acquisitions to produce digital 3D models, orthoimages, maps and other geometric representations useful for archaeological, architectural and communication needs. 3D reconstruction is often the preferred product to be delivered in archaeology and ancient building surveying.

In this work a detailed and reality-based 3D recording of the Milreu Roman ruins for documentation, conservation, preservation, restoration and visualization purposes were built from an imagery photo collection taken from a UAV. These models, accurate 3D data models and orthoimages, will be used to develop applications for: (i) interactive web3D navigations exploring the concept of gamification [1] and (ii) mobile devices superimposed with the real and virtual word, using virtual augmented reality.

The problems addressed in this paper are the reconstruction of the heritage site objects in the form of a realistically textured 3D model from areal and terrestrial images taken with uncalibrated cameras for the Web and mobile augmented reality platforms. The Sect. 2 presents the Milreu heritage site, Sect. 3 the UAV systems and image processing methods to produce $3 \mathrm{D}$ mesh models and point clouds. Section 4 is dedicated to show the results of the $3 \mathrm{D}$ modelling of the site and Sect. 5 the Web3d where the user can navigate the 3D model and the 3D point cloud in a browser. Finally, in Sect. 6 the results are discussed and the conclusions highlighted.

\section{Milreu}

The ruins of Milreu correspond to a Roman villa with a long period of occupation between the first and fifth centuries. It is one of the largest and best preserved Roman villas in the southwest of the peninsula, and is classified as a national monument since 1910, after the excavations of the 19th century carried out by the archaeologist Estácio da Veiga has revealed the archaeological importance of the site [15]. Since then, is a reference among the Portuguese archaeological 


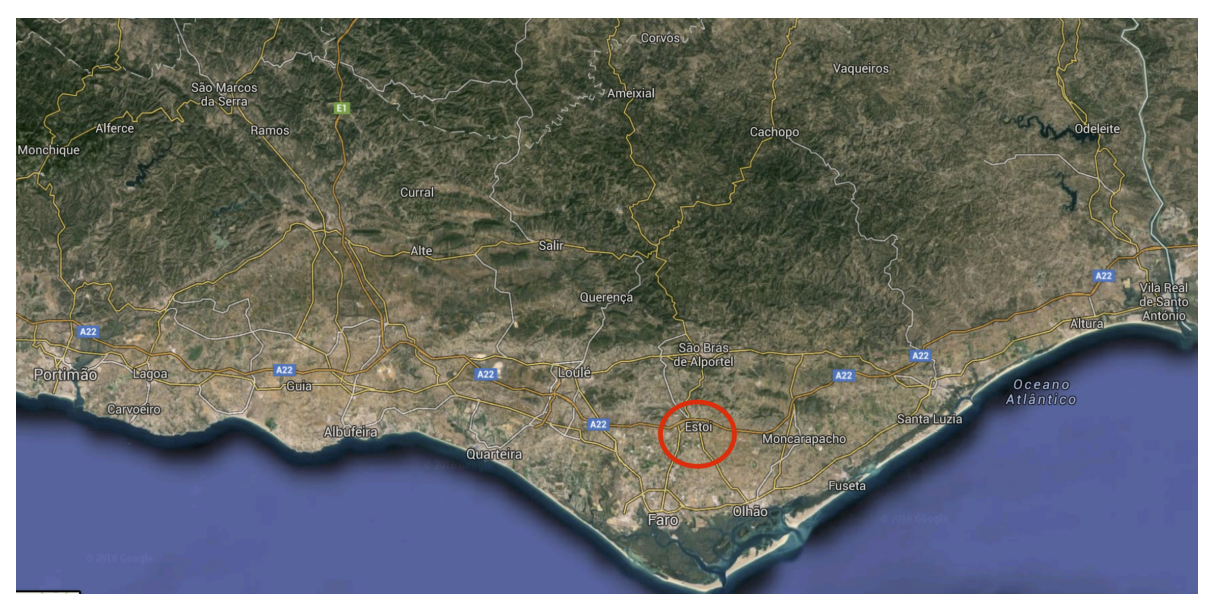

Fig. 1. Milreu ruins located in Estoi, $7 \mathrm{Km}$ from Faro. (source: Google maps)

sites, and from the $70 \mathrm{~s}$ of last century has an extensive program of excavations coordinated Theodor Hauschild. It is then that is definitely placed in sight the residential part and richest of the villa, the pars urbana, which was acquired by the State and made visitable to the public. This part visitable today include the mosaics with marine motifs, the temple, the baths and the residential area organized around a peristyle and a atrium [7,11]. The pars rustica, i.e. the part corresponding to the agricultural dependencies, stables and accommodation for slaves organized around a courtyard, clearly visible in 19th-century plant raised by Estacio da Veiga (Fig. 2), remains today occupied by agricultural land.

The site of Milreu constitutes a remarkable example of continuity of occupation over 2000 years, which is not limited, as it turned out, the ruins of the different phases of the Roman period but also the human occupations of different times. It is thus understandable that it is not easy to musealization a site with these characteristics and that the interpretation and presentation to the public of all its ruins into a coherent discourse is a complex task, since often some structures are inserted, interrupt or overlap structures from various eras.

According to the 2014 activities report of the Regional Direction of Culture of the Algarve, more than 15,000 visitors annually visit Milreu, of which almost $80 \%(78.6 \%)$ are foreigners. Despite having a circuit with explanatory panels of different parts that make up the ruins, it is difficult for the ordinary visitor to imagine the different volumetric and understand the relationship between the various dependencies. Sometimes, due to the interleaving of structures from different eras or the disappearance of parts of them, it becomes impossible for a visitor to have a correct idea of what it would be like in Roman times the appearance of buildings belonging those ruins. The use of UAVs technologies, to rigorous survey of structures, and subsequent reconstructions of 3D models, can allow visitors the cabal understanding of how were those ruins or how was the evolution of the site over time. Indeed, and for the times when there are historical 


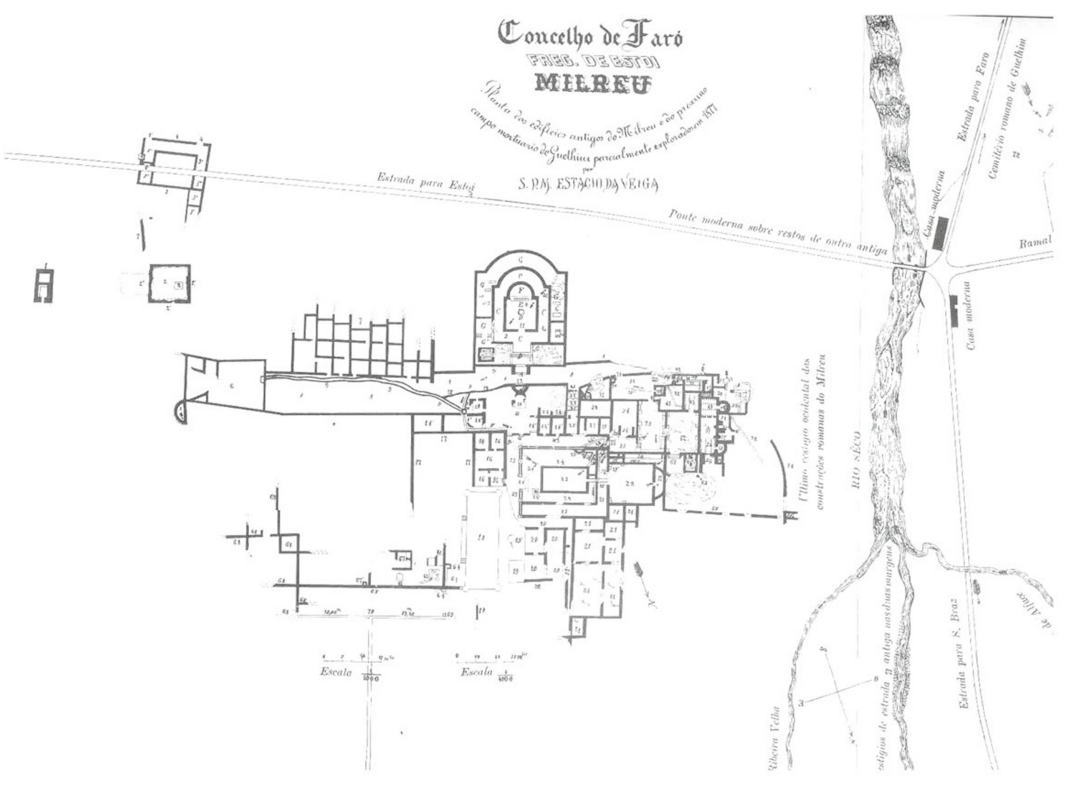

Fig. 2. 19th century plan of the Milreu Roman ruins [15].

and archaeological data, it is possible to reconstruct archaeological buildings or built sets, revealing that the ruins of a place like Milreu correspond, in fact, not one but several constructive realities that were happening and reflect our history of the last 2000 years.

This reconstruction from all the information available, in order to enable a better interpretation and reading of archaeological sites to visitors, is similar process to that of anastylosis, i.e. the re-composition of the dismembered parts of the historical monument, as already defined in The Athens Charter for the Restoration of Historic Monuments (October 1931). It is, however, a virtual anastylosis that, unlike the real one, can go further, to the total reconstruction of the building from unidentified elements but imagined, since the primary objective is to provide the visitor easy reading and closer to what the monument was (Fig. 3). And this, because the process is virtual, without ever compromising the identity and historical integrity of the object or reconstituted building.

\section{UAVs}

Unmanned aerial vehicles (UAV) or simply, drones are an emerging technology with autonomous navigation capability or remotely controlled, without human presence on the aircraft. Each vehicle includes several components including flight computer, sensors and actuators and payload such as cameras, thermal, multi- and hyper-spectral sensors or other equipment depending on the mission to accomplish. 


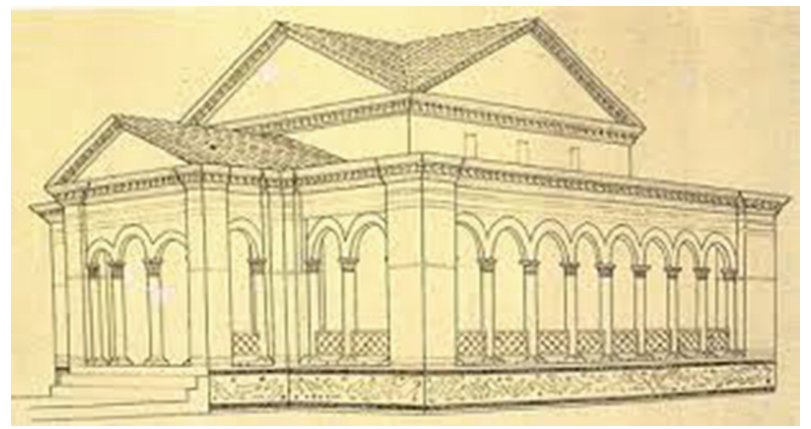

Fig. 3. Ancient Roman temple at Milreu [7].

The progressive miniaturisation capability made possible the production of high flexible mini- and micro-UAVs, equipped with navigation and autopilot systems that enable the independent execution of previously planned missions, assisted by a ground control station.

With these features, UAVs are good platforms for the acquisition of aerial images covering medium-sized areas, previously only accessible at higher costs and long planning cycles [6]. The versatility, the ease of operation, and the low costs of these small aircrafts enable its use in a large variety of applications such as agricultural and environmental applications, intelligence, surveillance, and reconnaissance, aerial monitoring in engineering, traditional surveying, conventional mapping and photogrammetry, and cultural heritage [3].

Traditional photogrammetric software requires a relatively intense human interaction, which is not suitable for processing large collections of photographs. To avoid such dependency, procedures such as structure from motion (SfM) [14] for automatic orientation of unordered image blocks obtained from UAV has been developed exploiting operators like SIFT [12] and SURF [2], which are invariant with respect to scale and rotations variations. Such methods are able to extract a set of manifold tie points to be used as observations in a photogrammetric bundle adjustment [4] to estimate camera parameters, whether or not the presence of GPS/INS (Global positioning system/Inertial navigation system) data. To select tie points these methods process pairs of overlapped and, since they consider all possible pairwise image combination in the block, $\frac{n(n-1)}{2}$ pairs of photos need to be processed. In this way complex image configurations and scenes can be dealt with, encompassing the use of convergent imagery, strong perspective deformations, lighting changes and so on.

Next step involves the dense reconstruction for generating point clouds from images and camera parameters and dense surface models for generating 3D mesh surfaces exploiting Multi-View Stereo techniques [17] combining computer vision and photogrammetry.

Usually, low-cost UAVs only carry sensors for position and orientation data (such as GPS and INS) with limited accuracy. Thus, for georeferencing the 3D 
meshes and point clouds accurately, the adopted techniques mainly rely upon ground control points (GCP), a well defined natural features or artificial marks surveyed with high precision.

\section{3D Modelling of the Cultural Heritage Site}

The adopted workflow to build the dense point cloud and the 3D mesh of the Milreu site starts with the planning of the flight and the selection of six well distributes GCPs in the area of the site.

The aerial photogrammetric survey to cover the site was realized by a DJI Phantom 3 Professional UAV system with an FC300X photo camera. FC300X is an RGB camera with 12 megapixels equipped with a $\mathrm{f} / 2.8$ lens, $94^{\circ}$ of field of view and $3.61 \mathrm{~mm}$ of focal length. The stabilization of the camera is assured by a 3 -axis gimbal mounted on the drone that also enables the system to take vertical and oblique photos.

The flights to collect photos had been done in October 2015, on a sunny day with some sparse clouds. The ruins were covered by a collection of 186 aerial near vertical photos with about $85 \%$ strip overlap and of $65 \%$ side overlap and pixel size of about $3.5 \mathrm{~cm}$ average. A second collection with 375 of very high oblique aerial photos around the ancient Roman temple was taken by the same UAV system. Finally, a third block of terrestrial photographs was taken with a Nikon D3000 SLR camera with an AF-S NIKKOR 18-55mm lens.

The three collected blocks of photos were processed by the SfM based software Agisoft/PhotoScan and Pix4D/Pix4Dmapper. These systems typically use GPS information for reconstruction initialization and apply an exhaustive matching approach for tie point extraction, which is needless for sequential imagery and computationally prohibitive for large image sequences due to its quadratic computational complexity. Both of the two software include in its workflows the ability to calculate the interior and exterior orientation parameters of each photo, produce dense point clouds, build a textured 3D mesh and produce georeferenced models using GCPs.

The Fig. 4 presents the textured point cloud obtained by the Agisoft/ Photoscan with the aerial vertical and oblique photographs. The ruins of the ancient roman temple of Fig. 3 can be seen at the left upper side in the model.

Both software were able to produce georeferenced textured dense point clouds and dense meshes from blocks with aerial vertical and oblique photos and terrestrial photos. In general, the Agisoft/Photoscan workflow takes more time to complete the tasks than Pix4D/Pix4D Mapper but the global quality of the models compare favorable to Photoscan. Pix4D Mapper is more effective to produce results in less time, but it required the definition of manual tie points using features visible in vertical, oblique and terrestrial photographs. 


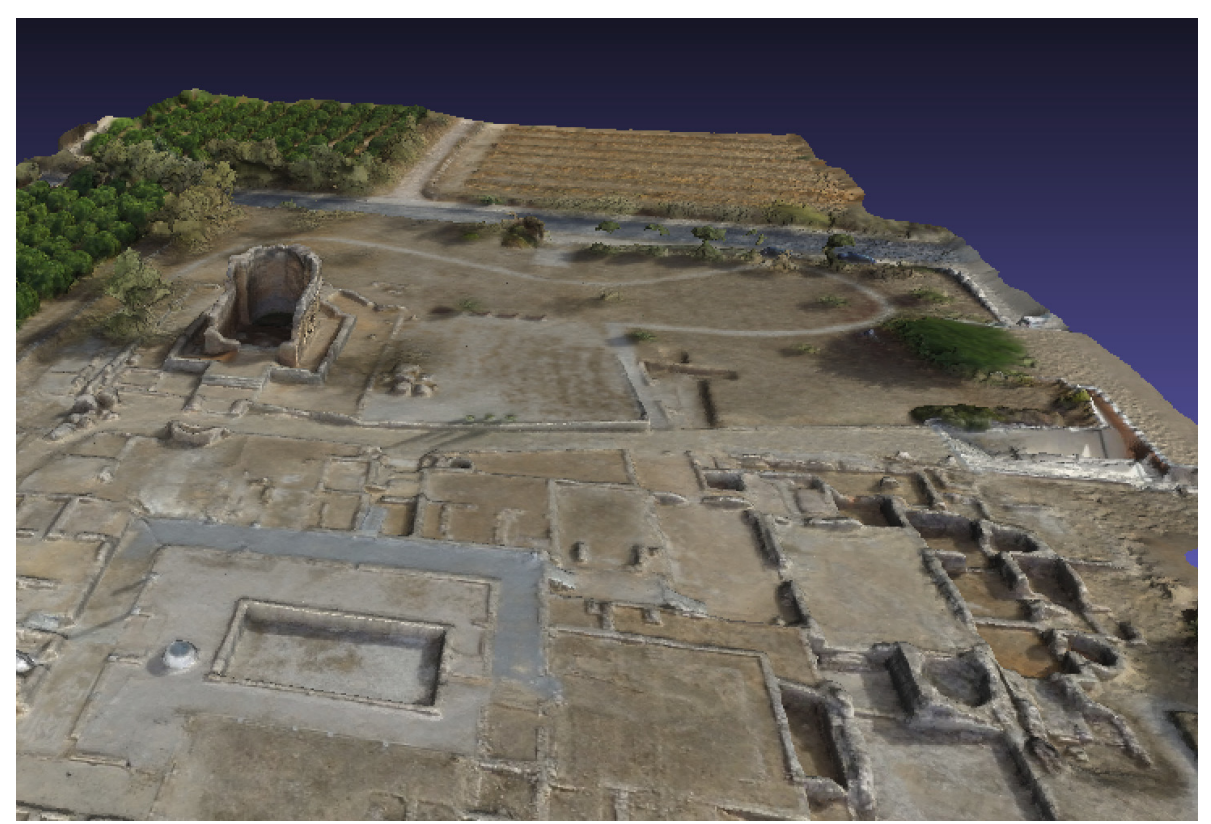

Fig. 4. 3D model of the Milreu Roman - general perspective of the site

\section{Web3D}

As a consequence of advances in computer hardware and internet connection speed, Web3D sites that include three-dimensional models where users navigate and interact through a 3D graphical interface, are increasingly employed in different domains. The possibility to publish 3D data on the Web is of particular interest for enabling researchers and the general public to visualize, navigate and interact with three-dimensional data on a simple Web browser.

In this work, we propose a framework available at http://geomatics.no-ip. org/milreu that uses HTML5, WebGL, and SceneJS to enable users to visualize and navigate the 3D models of the Milreu site produced with sets of aerial and terrestrial photographs.

HTML5 is the new markup language version published on October 2014 by the World Wide Web Consortium (W3C) [8], used to structure content on the World Wide Web. With this new version, the web browsers have become platforms with advanced graphics technologies and Javascript language support. WebGL (Web Graphics Library) is a JavaScript API for rendering interactive $3 \mathrm{D}$ and 2D graphics within any compatible web browser that can be used in HTML5, without any plugins. Finally, SceneJS is an open-source WebGL-based 3D visualization engine from @xeoLabs [9] with plugins to import 3D models 


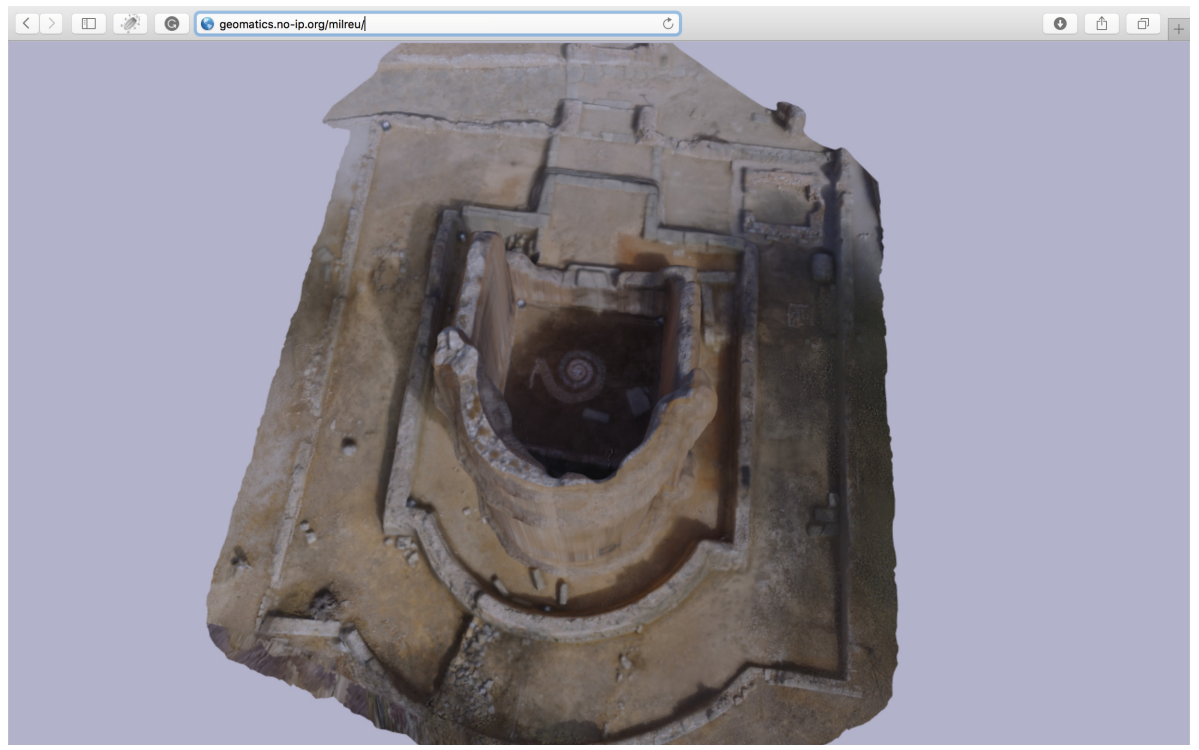

Fig. 5. 3D model of the temple in a browser

from geometry definition file formats such as the Wavefront .obj file, which is an open and a universally accepted format adopted by other 3D graphics application vendors.

The Fig. 5 presents a 3D model of the actual state of the ruins of the ancient roman temple in the Milreu heritage site available for visualization and navigation in a browser.

\section{Conclusions}

In this work, a workflow to produce georeferenced textured dense point clouds and 3D mesh models of the Milreu cultural heritage site in Faro, Algarve (Portugal) was developed and applied. These models were obtained combining sets of aerial photos, vertical and obliques taken from a UAV system, and blocks of terrestrial photos. The integration of these three types of photos has enabled complete and accurate 3D models more than the ones obtained processing each set of photos independently.

A framework for 3D visualization of the Milreu heritage site was made available on the Web using HTML5, WebGL, and SceneJS. Such solution does not require any additional plugins. The availability of Milreu Roman heritage in a Web3D is interesting for the geospatial field. Researcher and the general public can navigate in this environment to visualize at different scales the whole site and its structures. 


\section{References}

1. Baptista, E., Rodrigues, J., Figueiredo, M.: Culroute: Plataforma websig3d gamificada para seleção de roteiros turśsticos. Dos Algarves 26(2), 5-22 (2015)

2. Bay, H., Ess, A., Tuytelaars, T., Gool, L.V.: Speeded-up robust features (surf). Comput. Vis. Image Underst. 110(3), 346-359 (2008). Similarity Matching in Computer Vision and Multimedia

3. Colomina, I., Molina, P.: Unmanned aerial systems for photogrammetry and remote sensing: A review. ISPRS J. Photogrammetry Remote Sens. 92, 79-97 (2014)

4. Engels, C., Stewénius, H., Nistér, D.: Bundle adjustment rules. In: Photogrammetric Computer Vision (PCV), September 2006

5. Fiorillo, F., Fernńndez-Palacios, B.J., Remondino, F., Barba, S.: 3d surveying and modelling of the archaeological area of paestum, italy. Virtual Archaeol. Rev. 4(8), 55-60 (2013)

6. Gupta, S.G., Ghonge, M.M., Jawandhiya, P.M.: Review of unmanned aircraft system (UAS). Int. J. Adv. Res. Comput. Eng. Technol. (IJARCET) 2(4), 1646-1659 (2013)

7. Hauschild, T., Teichner, F.: Milreu - ruínas. Roteiros da Arqueologia Portuguesa. Instituto Português de Museus (2002)

8. Hickson, I., Berjon, R., Faulkner, S., Leithead, T., Navara, E.D., O'Connor, E., Pfeiffer, S.: Html 5: W3c recommendation, october 28, 2014. Techniocal report, W3C, October 2014. http://www.w3.org/TR/2014/REC-html5-20141028/

9. Kay, L.: Scenejs tutorials. Technical report, xeoLabs (2016). http://xeolabs.com/ articles/learning-scenejs/

10. Küng, O., Strecha, C., Beyeler, A., Jean-Christophe, F., D., Fua, P., Gervaix, F.: The Accuracy of Automatic Photogrammetric Techniques on Ultra-light UAV Imagery. In: UAV-g 2011 - Unmanned Aerial Vehicle in Geomatics (2011). http:// www.pix4d.com/

11. Lancha, J., Oliveira, C.: Corpus dos mosaicos romanos de Portugal / Corpus des mosaíques romaines du Portugal: II, Conventus pacensis: 2, Algarve Este, vol. 2. Universidade do Algarve (2013)

12. Lowe, D.G.: Distinctive image features from scale-invariant keypoints. Int. J. Comput. Vision 60(2), 91-110 (2004). http://dx.doi.org/10.1023/B: VISI.0000029664.99615.94

13. Remondino, F.: Heritage recording and $3 \mathrm{~d}$ modeling with photogrammetry and 3d scanning. Remote Sens. 3(6), 1104 (2011). http://www.mdpi.com/2072-4292/3/6/1104

14. Robertson, D.P., Cipolla, R.: Structure from Motion. Wiley, New York (2009)

15. Santos, M.: Arqueologia romana do Algarve, vol. II. Associação dos Arqueólogos Portugueses, Lisboa (1972)

16. Seitz, C., Altenbach, H.: Project archeye - the quadrocopter as the archaeologist's eye. In: ISPRS - International Archives of the Photogrammetry, Remote Sensing and Spatial Information Sciences XXXVIII-1/C22, 297-302: Conference on Unmanned Aerial Vehicle in Geomatics (UAV-g 2011). Zurich, Switzerland (2011)

17. Seitz, S.M., Curless, B., Diebel, J., Scharstein, D., Szeliski, R.: A comparison and evaluation of multi-view stereo reconstruction algorithms. In: 2006 IEEE Computer Society Conference on Computer Vision and Pattern Recognition, vol. 1, pp. 519528, June 2006 